\title{
LA ORDEN DEL HOSPITAL Y LA RECEPCIÓN DE LOS BIENES TEMPLARIOS EN LA PENÍNSULA IBÉRICA*
}

\author{
POR
}

\section{CARLos Barquero GoÑ}

Universidad Autónoma de Madrid

\begin{abstract}
REsumeN
Cuando el Temple fue disuelto en el Concilio de Vienne en 1312, el papa Clemente $\mathrm{V}$ incorporó los bienes templarios a los hospitalarios. Sin embargo, los reyes ibéricos se opusieron a este crecimiento del Hospital. Preferían fundar nuevas Ordenes Militares en sus reinos con las posesiones templarias. El pontificado tuvo que negociar con cada monarquía peninsular el destino de estas propiedades. Al final, los hospitalarios no recibieron nada en Portugal y muy poco en Castilla. Perdieron casi todos sus bienes en Valencia, pero las posesiones templarias en Navarra, Mallorca, Aragón y Cataluña fueron efectivamente trans. feridas a la Orden del Hospital.
\end{abstract}

\section{Abstract}

When the Temple was suppressed at the council of Vienne in 1312, Pope Clement V gave the Templar properties to the Hospitallers. However the Iberian kings were opposed to this growth of the Hospital. They wanted to found new Military Orders with the Templar possessions in their kingdoms. The Papacy had to deal with each Hispanic king the fate of these properties. The Hospitallers achieved nothing in Portugal and very little in Castile. They lost nearly all their goods in Valencia, but the Templar possessions in Navarre, Majorca, Aragon and Catalonia were effectively transfered to the Order of the Hospital.

* El presente trabajo ha sido realizado con la ayuda de una beca postdoctoral de la Fundación Caja de Madrid.

Proyección intemacional de la iglesia hispana Hispania Sacra 51 (1999) 


\section{INTRODUCCIÓN.}

La Orden del Temple y su disolución a comienzos del siglo XIV constituyen un episodio de la historia medieval de la Iglesia bastante conocido en sus rasgos generales'. La presencia de dicha Orden en la Peninsula Ibérica también ha sido bien estudiada ${ }^{2}$. Así mismo, en la actualidad contamos ya con varios trabajos sobre el proceso de los templarios en España ${ }^{3}$.

En cambio, la suerte posterior que corrió su patrimonio no ha despertado tanto interés bibliográfico. Tras la detención de los miembros de la Orden en 1307 los bienes templarios fueron secuestrados por las diferentes monarquías por orden del papa. Sabemos que tras la definitiva supresión del Temple en 1312, la mayor parte de sus posesiones en Europa pasaron a otra orden militar, la del Hospital o de San Juan, por decisión pontificia. Por supuesto, la transferencia de tal volumen de patrimonio eclesiástico se realizó con muchas dificultades. El caso de la Península Ibérica fue probablemente el más problemático de todos ${ }^{4}$. Por este motivo, nos ha parecido interesante realizar un estudio general sobre este trasvase de bienes eclesiásticos a gran escala en el conjunto peninsular.

\section{LA TEMPORAL EXCEPCIÓN IBERICA.}

En 1312 el papa Clemente V decidió incorporar los antiguos bienes templarios a la Orden del Hospital. Sin embargo, exceptuó de esta medida general a aquellos situados en los reinos y tierras de los reyes de Castilla, Aragón, Por-

\footnotetext{
I A. DEMURGER, Auge y caída de los Templarios, Barcelona 1986, 348 pp. M. BARBER, The trial of the Templars, Cambridge 1993, $312 \mathrm{pp}$.

2 A. J. FOREY, The Templars in the Corona de Aragon, Londres 1973, 498 pp. G. MARTÍNEZ DIEZ, Los templarios en la Corona de Castilla, Burgos 1993, 320 pp. J. M. SANS I TRAVE, Els templers catalans. De la rosa a la creu, Lérida 1996, 497 pp. Santos Agustín GARCía LARRAGUETA, El Temple en Navarra: Anuario de Estudios Medievales, 11 (1981) 635-661.

${ }^{3}$ Aurea JAVIERRE MUR, Aportación al estudio del proceso contra el Temple en Castilla: Revista de Archivos, Bibliotecas y Museos, 69 (1961) 47-100. Carlos ESTEPA, La disolución de la Orden del Temple en Castilla y León: Cuademos de Historia, 6 (1975) 121-186. Alan J. FOREY, The beginning of the proceedings against the Aragonese Templars: God and Man in Medieval Spain, eds. Derek W. Lomax y David Mackenzie, Warminster 1989, pp. 81-96. J. M. SANS I TRAVÉ, El procés dels Templers catalans. Entre el turment i la glòria, Lérida 1991, 334 pp. Gonzalo MARTíNEZ DfEZ, El proceso de disolución de los templarios. Su repercusión en Castilla: Los monjes soldados. Los templarios y otras órdenes militares, Aguilar de Campoo 1996, pp. 87-106.

4 J. DELAVILLE Le ROULX, Les Hospitaliers à Rhodes jusqu' à la mort de Philiben de Naillac (1310-1421), París 1913, pp. 28-50. A. LUTTRELL, The Hospitallers of Rhodes and their Mediterranean World, Aldershot 1992, III, pp. 67-86.
}

Proyección internacional de la iglesia hispana Hispania Sacra 51 (1999) 
tugal y Mallorca. El papa se los reservó para una futura disposición y ordenaciôn pontificia ${ }^{5}$.

Las razones de la excepción peninsular no son totalmente claras. La Orden de San Juan era la otra gran orden militar internacional existente en esta época cuyo desarrollo había sido, en gran medida, paralelo al del Temple ${ }^{6}$. En la Península Ibérica los hospitalarios también habían logrado una notable implantación durante los siglos XII y XIII. Ésta era especialmente intensa en los reinos orientales? Q Quizás por ello los monarcas peninsulares se oponían a que la Orden de San Juan ampliase su patrimonio en gran escala. Sabemos que presionaron de tal manera al papa que éste tuvo que retrasar su decisión al respecto. Los enviados de Jaime II de Aragón se distinguieron especialmente a este respecto. Parece que inicialmente los reyes peninsulares aspiraban a quedarse con los bienes templarios de sus respectivos territorios. En el caso aragonés influía mucho el temor a que la Ordeñ del Hospital adquiriese un excesivo poder. Con todo, la cuestión quedó momentáneamente aplazada, ya que el papa sólo concedió un tiempo a los monarcas ibéricos para que le comunicaran sus razonamientos y negociaran sobre el tema antes de tomar una decisión ${ }^{8}$.

Como vamos a tener ocasión de comprobar en las siguientes líneas, finalmente se van a definir dos posturas claramente enfrentadas sobre la cuestión: Por un lado, el pontificado deseaba incorporar los bienes templarios al Hospital para que siguieran cumpliendo su función de apoyo a la cruzada. Por el otro, los reyes peninsulares querían crear con ellos pequeñas órdenes militares en sus dominios estrechamente ligadas a la monarquía. La solución va a oscilar gradualmente en cada reino entre ambas posturas.

5 S. PAUL1, Codice diplomatico del sacro militare ordine Gerosolimitano, Lucca 1733-1737, II, pp. 23-26.

6 J. RILEY-SMITH, The knights of St. John in Jerusalem and Cyprus, c. 1050-1310, Londres $1967,553 \mathrm{pp}$.

7 S. GARcía LaRragueta, El gran priorado de Navarra de la Orden de San Juan de Jerusalén (Siglos XII-XIII). Pamplona 1957, I, 293 pp. M. L. LeDESMA RUBIO, La encomienda de Zaragoza de la Orden de San Juan de Jerusalén en las siglos XII y XIII, Zaragoza 1967, 619 pp. L. DAILLIEZ, L'Ordre de Saint-Jean de Jerusalem au Portugal XI-XV siècles, Niza 1977, 63 pp. P. BERTRAN I RolGE, LOrde de lHospital a les terres catalanes (Edat Mitjana): Actes de les primeres jornades sobre els ordes religioso-militars als països catalans (segles XII-XIX), Tarragona 1994, pp. 229-240. C. de AYALA MARTíNeZ (Compilador), Libro de privilegios de la Orden de San Juan de Jerusalén en Castilla y León (siglos XII-XV), Madrid 1995, $860 \mathrm{pp}$.

8 J. MIRET Y SANS, Les cases de Templers y Hospitalers en Catalunya, Barcelona 1910, pp. 378-381. A. LUTTRELL, The Hospitallers in Cyprus, Rhodes, Greece and the West 1291-1440, Londres 1978, XI, p. 6. M. L. LEDESMA RuBIO, Templarios y Hospitalarios en el Reino de Aragán, Zaragoza 1982, pp. 229-230. 


\section{LA APLICACIÓN DE LA SOLUCIÓN GENERAL EN NAVARRA.}

Navarra es el único reino ibérico que no fue exceptuado de la disposición general de Clemente $\mathrm{V}$ de entrega del patrimonio templario al Hospital. El motivo parece claro: en esta época Navarra políticamente estaba más ligada a Francia que al resto de la Península. El monarca navarro, Luis I, era el hijo primogénito del monarca francés 9 .

Así pues, Navarra es el único ejemplo ibérico de aplicación de las medidas pontificias generales sobre la cuestión de 1312. De hecho, entre los fondos documentales del priorato sanjuanista de Navarra se conserva uno de los originales múltiples de la bula de Clemente $V$ que disponía la entrega de los antiguos bienes templarios al Hospital con las excepciones mencionadas ${ }^{10}$. También en 1312 el mismo pontífice ordenó al obispo de Pamplona, al prior de Roncesvalles y al deán de la iglesia de Tudela que ayudasen a los hospitalarios a entrar en posesión de las propiedades del Temple ${ }^{11}$. El mismo año Clemente $\mathrm{V}$ escribió a los nobles del reino de Navarra para rogarles que facilitasen la transferencia de dicho patrimonio a la Orden de San Juan ${ }^{12}$.

Sin embargo, hubo que esperar a la autorización del monarca para que la transmisión se hiciera efectiva. El 20 de abril de 1313 Luis I ordenó a su gobernador de Navarra que entregara los antiguos bienes templarios existentes en el reino a los hospitalarios, expulsando de ellos a cualquier posible ocupante ilegal ${ }^{13}$. En cumplimiento del mandato regio, el 23 de junio siguiente Hugo de Visac, lugarteniente de gobernador en Navarra, ordenó a su vez al portero Miguel de Salinas que fuera a los lugares que habían sido del Temple en el reino y pusiera en posesión de los antiguos bienes templarios al prior navarro del Hospital $^{14}$. Al día siguiente el lugarteniente de gobernador redactó un mandato general de entrega de las mismas propiedades al prior del Hospital ${ }^{15}$.

La orden fue obedecida con prontitud. En efecto, se conservan dos documentos de toma de posesión de antiguos señoríos templarios por la Orden de San Juan en Navarra. Se trata de las dos principales villas que el Temple tenía

9 J. M. LACARRA, Historia política del reino de Navarra desde sus origenes hasta su incorporación a Castilla, Pamplona 1972, II, pp. 251-263.

10 Archivo Histórico Nacional, Sección de Ordenes Militares, carpeta 853, n. 58.

1 AHN, Ordenes Militares, carpeta 853, n. ${ }^{\circ}$ 57. S. PAULI, Codice diplomatico del sacro militare ordine Gerosolimitano, Lucca, 1733-1737, II, pp. 26-28.

12 AHN, Órdenes Militares, carpeta 853, n. ${ }^{\circ} 59$.

13 AHN, Órdenes Militares, carpeta 849, n.. 12.

14 AHN, Órdenes Militares, carpeta 919, n. ${ }^{\circ} 44$.

15 AHN, Ordenes Militares, carpeta 909, n.० 15. 
en el reino: Aberin y Ribaforada ${ }^{16}$. El 27 de junio de 1313 Miguel de Salinas, portero del rey, puso a don fray Pere de Chalderac, prior de la Orden de San Juan en Navarra, en posesión de la «casa» de Aberin y de todos los bienes muebles e inmuebles que la Orden del Temple poseía en todo el reino ${ }^{17}$. El 1 de julio siguiente el mismo Miguel de Salinas entrego el castillo, la iglesia y el señorío de la villa de Ribaforada al citado prior del Hospital y a otros miembros de la Orden ${ }^{18}$.

Sabemos que hubo problemas con la incorporación de alguna propiedad templaria de menor importancia ${ }^{19}$. Sin embargo, en general parece que Navarra fue el reino peninsular donde la recepción de los bienes del Temple por los hospitalarios se realizó con menos dificultades.

\section{LA «COMPRA» DE LOS BIENES EN MALLORCA.}

Mallorca fue el primero de los reinos exceptuados de la medida general aplicada en 1312 donde el problema de los bienes templarios encontró una solución. Sin embargo, el resultado final puso de manifiesto claramente las limitaciones de las pretensiones pontificias al respecto.

El rey de Mallorca, Sancho I, no llegó a enviar embajadores al papa en el plazo fijado para negociar la cuestión. Además, cuando finalmente se presentaron tres enviados del monarca ante el pontífice, la propuesta que trajeron no fue razonable para éste. Por ello Clemente $V$ decidió incorporar las propiedades templarias en su reino también a la Orden de San Juan en julio de 1313. El papa, incluso, escribió al rey Sancho I rogándole que prestara auxilio a los hospitalarios para que pudieran recibir aquellos bienes sin problemas ${ }^{20}$.

La propuesta rechazada consistía en que el monarca se quedase con varios dominios situados en la isla de Mallorca. Quizás como compensación, el pontífice otorgó al rey los bienes muebles templarios y las rentas producidas por los inmuebles desde el momento de su secuestro. Esta concesión se haría efectiva cuando el soberano hubiera restituido a los hospitalarios todas las posesiones

\footnotetext{
16 SANTOS García LARRagueta, El Temple en Navarra: Anuario de Estudios Medievales, 11 (1981), 650 y 661 .

${ }^{17}$ AHN, Ordenes Militares, carpeta 919, n. ${ }^{\circ} 44$.

18 AHN, Ordenes Militares, carpeta $909, n .^{\circ} 15$.

19 Santos GaRcía LARRAGUETA, La Orden de San Juan de Jerusalén en Navarra. Siglo XIV: Las Órdenes Militares en el Mediterráneo Occidental (S. XII-XVHI), Madrid 1989, pp. 109-110.

${ }^{20}$ S. PAULI, Codice diplomatico del sacro militare ordine Gerosolimitano, Lucca 1733-1737, II, pp. 395-398.
} 
del Temple. Sin embargo, esta solución no satisfizo al rey, que siguió manteniendo sus pretensiones ${ }^{21}$.

Al final la Orden de San Juan tuvo que negociar directamente con el monarca mallorquín. El encargado de hacerlo fue frey Arnaldo de Soler, un hospitalario que mantenía una buena relación con Sancho I. El acuerdo se materializó en febrero de 1314. El rey de Mallorca renunció a sus derechos sobre los bienes del Temple. A cambio, la Orden de San Juan le pagó 22.500 sueldos reales mallorquines y se comprometió a abonarle una renta anual de otros 9.000 sueldos reales mallorquines y de 2.000 sueldos barceloneses. De esta forma, el Hospital pudo recibir todo el patrimonio templario del reino de Mallorca en $1314^{22}$.

Al parecer, la Orden de San Juan tuvo que hacerse cargo del mantenimiento de los antiguos miembros de la Orden del Temple en este reino al incorporar sus bienes. Al final del Concilio de Vienne de 1312 se había decidido que los templarios que fueran encontrados inocentes recibirían una pensión para su subsistencia con cargo a las propiedades de su Orden ${ }^{23}$. En el caso de Mallorca un testimonio nos indica que el Hospital asumió efectivamente esta carga al recibir su patrimonio. El 4 de enero de 1317 Guillermo de Soler, miembro en otro tiempo de la Orden del Temple, reconocía que había recibido de frey Arnaldo de Soler, comendador hospitalario de Mallorca, 22 libras y media. Dicha cantidad le había sido satisfecha en pago de los 300 torneses de plata que el comendador le debía haber dado el 25 de diciembre anterior en razón de la provisión que Guillermo disfrutaba sobre los antiguos bienes templarios ${ }^{24}$.

\section{LA SOLUCIÓN PACTADA DE ARAGÓN.}

En la Corona de Aragón la cuestión de los bienes templarios va a ser objeto de una larga y compleja negociación entre el rey y el papa. Por un lado, el monarca aragonés Jaime II quería fundar con ellos un nuevo convento de la Orden de Calatrava en el reino de Valencia que defendiera sus dominios meridionales de las incursiones musulmanas. Por el otro, el pontífice deseaba incorporar todas estas posesiones a la Orden del Hospital. La solución final va a ser una vía intermedia entre ambas posturas ${ }^{25}$.

21 J. Delaville Le RoulX, Les Hospitaliers à Rhodes jusqu'à la mon de Philibert de Naillac (1310-1421), París 1913, pp. 42.43.

22 J. M. SANS I TRAVÉ, El procés dels Templers catalans. Entre el turment i la glòria, Lérida 1990, pp. 300-301.

${ }_{23}$ M. BARBER, The Trial of the Templars, Cambridge 1993, p. 238.

24 AHN, Ordenes Militares, carpeta 528, n. ${ }^{\circ} 689$.

25 J. MIRET Y SANS, Les cases de Templers y Hospitalers en Catalunya, Barcelona 1910, pp. 378-383. A. L. JAVIERRE MUR, Privilegios reales de la Orden de Montesa en la Edad Media, Madrid 
El 15 de febrero de 1317 Jaime II nombraba procurador suyo a Vidal de Vilanova para tratar con el papa Juan XXII la suerte de los bienes templarios de sus reinos ${ }^{26}$. Dos meses después había ya un borrador que recogía los principales puntos en que iba a basarse el arreglo final. El 26 de abril el monarca aragonés escribía a Vidal de Vilanova dando su visto bueno o haciendo observaciones a una serie de «capítulos» que le había enviado su embajador del pacto que negociaba con el pontífice sobre el destino del patrimonio del Temple en Aragón ${ }^{27}$.

El acuerdo definitivo se materializó el 10 de junio de 1317. Con esta fecha Juan XXII fundó un monasterio de la Orden de Calatrava en el castillo de Montesa al cual incorporó casi todos los bienes del Temple y del Hospital existentes en el reino de Valencia. Tan sólo exceptuó los que la Orden de San Juan tenía en la ciudad de Valencia y en su ternitorio en un radio de media legua alrededor, y el castillo y la villa de Torrente ${ }^{28}$. Simultáneamente, el papa concedió al Hospital las antiguas posesiones templarias situadas en el reino de Aragón y en Cataluña. Sin embargo, el pontífice también impuso a los priores y comendadores sanjuanistas a partir de entonces la obligación de prestar juramento de fidelidad y homenaje al monarca aragonés antes de entrar en posesión de sus cargos en la Corona de Aragón ${ }^{29}$. La mayor parte de las citadas resoluciones pontificias fueron formalmente comunicadas el 10 de agosto siguiente por el cardenal Berenguer, obispo de Frascati, a Vidal de Vilanova y al castellán de Amposta, frey Martín Pérez de Oros, quien era el máximo dignatario de la Orden del Hospital en Aragón. Ambas personalidades manifestaron entonces su disposición para ejecutarlas y obedecerlas ${ }^{30}$.

De todas formas, inmediatamente después el papa tomó diversas medidas para asegurar el correcto cumplimiento de estas decisiones. El 11 de junio de 1317 Juan XXII encomendó al obispo de Tortosa, al abad del monasterio de Santa María de Valldigna y al chantre de la Catedral de Gerona la tarea de cuidar que los bienes valencianos del Temple y del Hospital estuvieran libres de toda carga cuando los recibiese el nuevo monasterio calatravo de Monte-

\footnotetext{
s. a., pp. 11-13. M. L. LEDESMA RUBlo, Templarios y Hospitalarios en el Reino de Aragón, Zaragoza 1982, pp. 229-234. ENRIC GUINOT RODRÍGUEZ, La fundación de la Orden Militar de Santa María de Montesa: Saitabi, 35 (1985) 73-86. J. M. SANS I TRAVÉ, El procés dels Templers catalans. Entre el turment i la glòria, Lérida 1990, pp. 285-298. J. M. SANS I TRAVÉ, Els Templers catalans. De la rosa a la creu, Lérida 1996, pp. 465-470.

26 J. VILLARROYA, Real Maestrazgo de Montesa, Valencia 1787, II, pp. 9-11.

${ }^{27}$ AHN, Órdenes Militares, carpeta 484, n. ${ }^{\circ} 194$.

28 H. DE SAMPER, Montesa ilustrada, Valencia 1669, L, pp. 17-24.

${ }^{29}$ S. PAULI, Codice diplomatico del sacro militare ordine Gerosolimitano, Lucca, 1733-1737, II, pp. 51-56.

30 J. Villarroya, Real Maestrazgo de Montesa, Valencia 1787, II, pp. 12-15.
} 
$\mathrm{sa}^{31}$. El 12 de agosto siguiente el mismo pontífice rogó al rey de Aragón, Jaime II, que revocase todas las obligaciones y enajenaciones que hubiera hecho sobre los bienes templarios de su reino que debían pasar a la Orden de San Juan, y que entregase dichas posesiones absolutamente libres de toda carga ${ }^{32}$. Finalmente, el 11 de mayo de 1318 el papa encargó al arzobispo de Tarragona, al arcediano de Zaragoza y a Berenguer de Alvemia, canónigo de Beziers, que pusieran a los hospitalarios en posesión de los bienes del Temple situados en Cataluña y en el reino de Aragón ${ }^{33}$.

Al igual que había hecho con el rey de Mallorca, Juan XXII también decidí ceder al monarca aragonés los bienes muebles y las rentas producidas por el patrimonio del Temple durante su secuestro, en consideración a los gastos ocasionados por su incautación. El 1 de octubre de 1317 el papa mandó al arzobispo de Tarragona y a los obispos de Zaragoza y de Tortosa que remitieran todo aquello a Jaime II después de que las posesiones templarias de Aragón y Cataluña fueran restituîdas a los hospitalarios ${ }^{34}$.

El proceso de transferencia de propiedades previsto en la Corona de Aragón comenzó el 22 de noviembre de 1317. Ese día el castellán de Amposta, frey Martín Pérez de Oros, prestó juramento de fidelidad y de homenaje al rey de Aragón en cumplimiento de lo que había dispuesto el pontífice el 10 de junio anterior ${ }^{35}$. En la misma jornada Jaime II ordenó al castellán que entregase a dos consejeros suyos los bienes sanjuanistas del reino de Valencia con destino al nuevo monasterio de Montesa: a Gonzalo García los situados al Sur del Guadalaviar y a Pedro Boil los emplazados al Norte de dicho río ${ }^{36}$.

Parece que la mayor parte del patrimonio valenciano del Hospital fue transmitido con bastante rapidez ${ }^{37}$. El caso de la bailía de Cervera del Maestre puede ser un buen ejemplo. El 24 de noviembre de 1317 el castellán de Amposta mandó a su lugarteniente Sancho de Orós, comendador de Calatayud, que entregara la citada bailía a Pedro Boil. Tres días más tarde, el propio Pedro Boil escribió a Sancho de Orós para rogarle que diera la bailía a su hijo Ramón

31 AHN, Ordenes Militares, carpeta 503, n.*37. H. DE SAMPER, Montesa ilustrada, Valencia 1669, I, pp. 28-29. J. VILlaRRoYA, Real Maestrazgo de Montesa, Valencia 1787, II, pp. 11-12.

32 AHN, Ordenes Militares, carpeta 597, n.. 79.

33 AHN, Órdenes Militares, carpeta 597, п.. 82.

${ }^{34} \mathrm{AHN}$, Ordenes Militares, carpeta $503, \mathrm{n} .{ }^{\circ} 40$.

35 AHN, Órdenes Militares, carpeta 528, n." 692.

36 H. DE SAMPER, Montesa ilustrada, Valencia 1669 , I, pp. 39-40.

37 J. Villarroya, Real Maestrazgo de Montesa, Valencia 1787, I, p. 26. Sobre la magnitud de este patrimonio, véanse E. GUINOT RODRÍGUEZ, Feudalismo en expansión en el norte valenciano. Antecedentes y desarrollo del seftorio de la Orden de Montesa. Siglos XIII y XIV, Castellón 1986, pp. 20-29 y A. L. JAvierRe MuR, Privilegios reales de la Orden de Montesa en la Edad Media, Madrid s. a., pp. $65-66,68,71,76-81$.

Proyección intemacional de la iglesia hispana Hispania Sacra 51 (1999) 
de Boil en su nombre ${ }^{38}$. Finalmente la entrega se produjo el 3 de diciembre siguiente ${ }^{39}$

Posteriormente todos estos antiguos bienes sanjuanistas fueron efectivamente entregados por la monarquía a la nueva Orden de Montesa ${ }^{40}$. Como prescribían las disposiciones pontificias, la Orden del Hospital tan sólo retuvo la encomienda de Torrente y la iglesia de San Juan del Hospital en la capital dentro del reino de Valencia ${ }^{41}$.

Sin embargo, sí sabemos que se plantearon algunos problemas en los años inmediatamente posteriores a la entrega en relación a las posesiones transmitidas. En primer lugar, parece que los hospitalarios previamente vendieron algunas rentas o dejaron ciertas propiedades gravadas con cargas. El 23 de marzo de 1319 el rey Jaime II tuvo que escribir a su administrador de los antiguos bienes templarios y hospitalarios del reino de Valencia, Bernardo Columbi, para que hiciera cumplir su cometido a los prelados encargados por el papa de impedirlo ${ }^{42}$. También sabemos que quedó pendiente de entrega el priorato de Castielfabit. El 8 de diciembre del mismo año el monarca aragonés hubo de requerir al castellán de Amposta para que lo diera al clavero de la Orden de Montesa, frey Erimano de Erolis, junto con las rentas percibidas desde el tiempo en que debía haber sido cedido ${ }^{43}$.

Curiosamente, el mayor problema parece que fue que los hospitalarios se quedaron con la documentación relacionada con los bienes entregados. El castellán de Amposta prometió enviarla al rey antes del fin del mes de noviembre de 1319, pero finalmente no lo hizo. El 8 de diciembre de 1319 Jaime II tuvo que mandar al castellán que le remitiese inmediatamente todas las escrituras tocantes a las villas, castillos y lugares asignados al monasterio de Montesa ${ }^{44}$. Frey Martín Pérez de Oros efectivamente al final entrego algunas, pero otras quedaron en el castillo sanjuanista de Ulldecona. El 31 de enero de 1320 el monarca hubo de ordenar a frey Guillermo Rabaza, comendador hospitalario de Amposta, que las cediese a Pedro López de Balanyano, escriba del

\footnotetext{
38 H. DE SAMPER, Montesa ilustrada, Valencia 1669, I, pp. 40-4I.

39 E. SANCHEZ ALMELA, El Libre de privilegis de la Villa de Sant Mateu (1157-1512), Castellón 1985, pp. 171-176.

40 ENRIC GUEOT RoDrígueZ, La fundación de la Orden Militar de Santa María de Montesa: Saitabi, 35 (1985) 80-86. LuIs GARcía-GulJARro RAMOS, Los onígenes de la Orden de Montesa: Las Órdenes Militares en el Mediterráneo Occidental (S. XII-XVHI), Madrid 1989, 69-83.

41 F. LlORCA, San Juan del Hospital de Valencia. Fundacion del siglo XIII, Valencia 1930, 145 pp. J. RoYo MARTíNEZ, Un señorio valenciano de la Orden del Hospital. La encomienda de Torrent, Horta-Sud 1988, $189 \mathrm{pp}$.

42 H. DE SAMPER, Montesa llustrada, Valencia 1669, I, pp. 42-44.

${ }^{43}$ AHN, Ordenes Militares, carpeta 485, n. 207.

44 AHN, Ordenes Militares, carpeta $485, n, 205$ bis.
} 
monasterio de Montesa. Previamente, el 19 de enero anterior, Jaime II también había mandado a frey Arnaldo de Soler, comendador sanjuanista de Aliaga, que envíase a su curia los privilegios y documentos que tuviera sobre el priorato de Castielfabit y cualesquier otros que interesaran a la Orden de Montesa ${ }^{45}$.

Mientras todo esto sucedía en el reino de Valencia, de forma paralela había tenido lugar la transferencia del antiguo patrimonio del Temple en el reino de Aragón y en Cataluña a la Orden del Hospital. La transmisión había sido preparada con bastante antelación. Sabemos que en mayo de 1317 el maestre racional, Pere Boyl, ya daba instrucciones al administrador real de la encomienda templaria de Granyena, Pedro de Cardona, para que la entregase al castellán de Amposta el 19 de diciembre siguiente ${ }^{46}$.

En efecto, el proceso de transferencia se inició a fines de aquel año. El $1 \mathrm{de}$ diciembre de 1317 Jaime II mandaba a Guillermo de Ciqueriis, baile general de Cataluña, y a Miguel de Roca, portero real, que hicieran entregar todas las antiguas posesiones del Temple existentes en Cataluña al castellán de Amposta, Martín Pérez de Oros. El 17 de diciembre siguiente los dos interesados delegaban sus funciones en Guillermo de Rivo Oulo, administrador real de las encomiendas de Gardeny y de Corbins, para que éste diera posesión de la encomienda de Gardeny al citado castellán o a sus representantes ${ }^{47}$. Órdenes parecidas debieron impartirse para el reino de Aragón de forma simultánea.

Inmediatamente después empezamos a tener testimonios de la recepción por los hospitalarios de diversas propiedades templarias en Cataluña y Aragón. Al principio fue el propio castellán de Amposta quien personalmente fue haciéndose cargo de ellas. El 2 de diciembre de 1317 frey Martín Pérez de Oros entraba en posesión de la casa y de los bienes que fueron de la Orden del Temple en la ciudad de Tortosa ${ }^{48}$. El 5 de diciembre siguiente el mismo castellán tomó posesión del antiguo castillo templario de Miravet. Inmediatamente después recibió el homenaje y el juramento de fidelidad de la aljama de los mudéjares del lugar ${ }^{49}$. Tres días después los jurados de Ascó y de Ribarroja, en nombre de los concejos de aquellas localidades, también prestaron homenaje y

45 AHN, Órdenes Militares, carpeta $485, n^{\circ} 216$.

46 TOMÁS DE MONTAGUT I ESTRAGUÉs, El Reial Patrimoni i els béns del Temple (1307-1317): Actes de les primeres jomades sobre els ordes religioso-militars als paisos catalans (segles XII-XIX), Tarragona 1994, pp. 152-153.

47 J. MIRET Y SANS, Les cases de Templers y Hospitalers en Catalunya, Barcelona 1910, pp. 387-388.

48 M. BEguer PINYOL, El Real Monasterio de Santa Maria de la Rápita de la sagrada y soberana Orden de San Juan de Jerusalén, Tortosa 1948, p. 284.

${ }^{49}$ AHN, Ordenes Militares, carpeta 610, n. ${ }^{9} 92$.

Proyección internacional de la iglesia hispana

Hispania Sacra 51 (1999) 
juramento de fidelidad a frey Martín tras tomar éste posesión de la antigua bailía templaria de $\mathrm{Ascó}^{50}$.

Posteriormente el castellán delegó en otro oficial hospitalario la tarea que él había iniciado. El elegido fue el comendador de Calatayud y de Cantavieja, frey Sancho de Oros, quien también era lugarteniente del castellán. El 20 de diciembre de 1317 ya era frey Sancho quien recibía el homenaje y el juramento de fidelidad de los hombres y del concejo de Chalamera, tras tomar posesión de esta villa anteriormente templaria ${ }^{51}$. El mismo proceso se repitió en Cantavieja el 30 de diciembre siguiente ${ }^{52}$. Finalmente, sabemos que el comendador de Calatayud y de Cantavieja tomó posesión del castillo y del lugar de Alfambra el 6 de enero de 1318. El mismo día sus habitantes le prestaron homenaje y juramento de fidelidad ${ }^{53}$. En general, todo el proceso fue muy similar al de la recepción por la Orden de Montesa de las posesiones que la correspondieron entre 1319 y $1320^{54}$.

Parece que a medida que los oficiales reales fueron transmitiendo los antiguos bienes temporales del Temple a los hospitalarios, el episcopado también fue haciendo lo mismo con las iglesias. El 30 de marzo de 1318 el obispo de Zaragoza, Pedro, mandó al arcipreste de Zaragoza, Gombaldo de Vergua, que entregara las iglesias de Novillas, Añesa, Alberite, Encinacorba y Boquiñeni al castellán de Amposta, Martín Pérez de Oros. Da la impresión de que la orden fue cumplida con rapidez. El 5 de abril siguiente Calbet Jiménez de Aisa, clérigo y lugarteniente del arcipreste zaragozano, ya ponía en posesión del templo de Encinacorba a frey Bernart de Cetina, prior sanjuanista de Grisén y procurador del castellán ${ }^{55}$.

Al terminar la primera mitad del año 1318 parece que los hospitalarios aragones ya habían ocupado la mayor parte de los bienes templarios que les correspondían. El 7 de junio frey Martín Pérez de Oros, castellán de Amposta, reconocía a Jaime II que había recibido del monarca las posesiones del Temple situadas en Cataluña y en el reino de Aragón ${ }^{56}$. En realidad, sin embargo, la transmisión no estaba completada en su totalidad en esta fecha. Varias eviden-

${ }^{50}$ AHN, Ordenes Militares, carpeta 636, n. ${ }^{\circ} 18$

${ }^{51}$ AHN, Ordenes Militares, carpeta $660, n .^{\circ} 4$.

52 Eloy BENITO RUANO, La encomienda templaria y sanjuanista de Cantavieja (Teruel): Homenaje a don José María Lacarra de Miguel en su jubilación del profesorado. Estudios medievales III, Zaragoza 1977 , pp. 163-165.

${ }^{53}$ AHN, Órdenes Militares, carpeta $616, n .{ }^{\circ} 8$ bis.

54 Enric Guinot RODRjguez, La fundación de la Orden Militar de Santa María de Montesa: Saitabi, 35 (1985) 82-85. LUIS GARClA-GUIJARRO RAMOS, Los origenes de la Orden de Montesa: Las Ordenes Militares en el Mediterráneo Occidental (S. XIL-XVII), Madrid 1989, pp. 72-74, 76-77.

53 AHN, Órdenes Militares, carpeta 661, n.. 18.

56 AHN, Ordenes Militares, carpeta 528, n. 694. 
cias así nos lo demuestran. El 21 de agosto el propio Jaime II tenía que ordenar a sus oficiales del reino de Aragón y Ribagorza que no impidiesen a los hospitalarios cobrar las rentas que antes habían sido de los templarios, aunque no dispusieran de título de posesión. Incluso, el monarca hubo de repetir el mismo mandato al sobrejuntero de Huesca y Jaca, al justicia y al baile de Huesca el 28 de enero de $1319^{57}$. Por su parte, uno de los clérigos a quienes el papa había encargado la verificación de la transferencia, el canónigo de Beziers Berenguer de Alvernia, todavía el 27 de octubre de 1318 ordenaba a todos los detentadores de bienes templarios en los reinos y tierras del rey de Aragón que los entregasen al castellán de Amposta en el plazo de dos meses. En caso contrario, sufrirían censuras eclesiásticas. Además, Berenguer nombró representantes suyos a varios prelados aragoneses para que ejecutasen el mandato ${ }^{58}$.

Sabemos que, en efecto, la transmisión de ciertas posesiones se demoró algún tiempo. Por ejemplo, la antigua encomienda templaria de Torres de Segre parece que no fue entregada al Hospital hasta el año $1320^{59}$. Todavía en 1340 el papa Benedicto XII rogaba al rey Pedro IV de Aragón que diera a la Orden de San Juan las casas que habían sido de los templarios y, en especial, la de Horta, conforme al acuerdo de $1317^{60}$.

Incluso hubo alguna villa del Temple que no llegó a transferirse. Éste parece haber sido el caso de Alfocea. En 1319 Jaime II ordenaba que no se exigiera al comendador sanjuanista de la antigua casa del Temple de Zaragoza el pago del tributo real de la cena correspondiente a los hombres de Alfocea hasta que el monarca no devolviera dicho lugar al Hospital ${ }^{61}$. La restitución de Alfocea a la Orden no llegó a producirse. En 1327 Jaime II vendió la villa a Ferrer de la Nuza por 23.000 sueldos jaqueses ${ }^{62}$. Todavía a fines del siglo XV los hospitalarios presentaron una demanda en Roma contra los entonces señores de Alfocea, Martín Díaz de Aux y su madre, para conseguir la devolución de la villa. Sin embargo, el rey Fernando el Católico intervino de forma decidida para impedir la tramitación de la causa en $1493^{63}$.

\footnotetext{
${ }^{57}$ AHN, Órdenes Militares, carpeta 589, n.. 172.

58 AHN, Órdenes Militares, carpeta 597, n. ${ }^{\circ} 84$.

59 Marc EsCOLÀ-PAU TUTUSAUS, Del canvi Temple-Hospital a la Comanda de Torres de Segre (Segrià), 1307-1320: Actes de les primeres jornades sobre els ordes religioso-militars als paitsos catalans (segles XII-XIX), Tarragona 1994, p. 217.

${ }^{60}$ F. J. MiQuell ROSELl, Regesta de letras ponificias del Archivo de la Corona de Aragón. Sección Cancilleria Real (Pergaminos), Madrid 1948, pp. 294-295.

${ }^{61}$ AHN, Códices, 659-B, p. 53.

62 AHN, Códices, 659-B, pp. 42-48.

${ }^{63}$ A. DE LA TORRE (Ed,), Documentos sobre relaciones internacionales de los Reyes Catolicos, Barcelona 1949-1966, IV, pp. 103-104, 265-266.
}

Proyección internacional de la iglesia hispana Hispania Sacra 51 (1999) 
De todas formas, es indudable que el patrimonio sanjuanista en la Corona de Aragón experimentó un fuerte crecimiento gracias a la incorporación de los bienes templarios del reino de Aragón y de Cataluña. Este aumento compensó sobradamente las pérdidas sufridas por la entrega de la mayoría de las posesiones valencianas del Hospital a la nueva Orden de Montesa. De hecho, el número de encomiendas sanjuanistas se multiplicó ${ }^{64}$. Además, parece que también creció considerablemente el tamaño de algunas de ellas. El caso estudiado de la encomienda de Zaragoza así nos lo demuestra ${ }^{65}$.

El enorme aumento experimentado de esta forma por el patrimonio hospitalario obligó a un reajuste administrativo. En 1319 el maestre de la Orden, Helión de Vilanova, tuvo que desgajar parte de la castellanía de Amposta para crear otra circunscripción sanjuanista del mismo nivel: el priorato de Cataluña. El motivo aducido por el maestre era que tras la incorporación de los bienes templarios la castellanía no podía ser convenientemente gobernada por una sola persona debido a la multitud de lugares que abarcaba. El límite entre ambas circunscripciones fue colocado en el río Ebro y en la localidad de Almacelles ${ }^{66}$.

Sin embargo, la transferencia de las posesiones templarias del reino de Aragón y de Cataluña no sólo supuso ventajas para los hospitalarios. También tuvieron que soportar una carga aneja a ellas durante algún tiempo. En 1312 un Concilio provincial reunido en Tarragona había declarado inocentes a los antiguos templarios de la Corona de Aragón y les había asignado pensiones vitalicias con cargo a sus anteriores posesiones ${ }^{67}$. Más adelante, en 1317 , el papa Juan XXII ordenó el traslado de las pensiones que estuvieran situadas sobre antiguos bienes del Temple en el reino de Valencia a otras posesiones de la misma Orden en el reino de Aragón y en Cataluña ${ }^{68}$. Cuando los hospitalarios tomaron posesión de su patrimonio también asumieron esta carga. En efecto,

64 J. MiRET y SANS, Les cases de Templers y Hospitalers en Catalunya, Barcelona 1910, pp. 387-389. M. L. LEDESMA RUBIO, Templarios y Hospitalarios en el Reino de Aragón, Zaragoza 1982, pp. 231-232.

65 MARja LUISA LEDESMA RUBIO, Las propiedades de la Orden del Hospital en Zaragoza, tras la incorporación de los bienes del Temple: Cuademos de Aragón, 18-19 (1984) 148-150. MARLA LUISA LEDESMA RUBIO, La Orden de San Juan de Jerusalén en Zaragoza en el siglo XIV: La Ciudad de Zaragoza en la Corona de Aragón. Comunicaciones. X Congreso de Historia de la Corona de Aragón, Zaragoza 1984, pp. 384-386.

66 AHN, Ordenes Militares, carpeta 859, n. $^{\circ} 7$

67 M. L. Ledesma Rub10, Templarios y Hospitalarios en el Reino de Aragón, Zaragoza 1982, p. 229. J. M. SANS I TRAVÉ, El procés dels Templers catalans. Entre el turment i la glòria, Lérida 1991, pp. $282-283$.

68 J. VillarRoYa, Real Maestrazgo de Montesa, Valencia 1787, II, pp. 11-12. 
se conservan varios testimonios sobre el pago de pensiones a antiguos templarios por los hospitalarios aragoneses ${ }^{69}$.

Precisamente uno de los mayores problemas que suscitó el desgajamiento del priorato de Cataluña a partir de la castellanía de Amposta fue el reparto de esta carga. En 1319 una avenencia estableció la división en una proporción de $7 / 12$ para la castellanía y $5 / 12$ para el priorato. La suma total que debían pagar anualmente por este concepto ascendía a la respetable suma de 136.050 sueldos barceloneses ${ }^{70}$. El castellán de Amposta no se quedó satisfecho con el reparto y en 1320 inició un pleito contra el prior de Cataluña ante el juez comisionado al efecto por el maestre de la Orden, el prior de Navarra ${ }^{71}$. Por desgracia, desconocemos el resultado final de esta reclamación.

En cualquier caso, lo que es indudable es que la incorporación de los bienes templarios de Cataluña y del reino de Aragón a la Orden de San Juan tuvo como consecuencia un contrọl más estrecho de los hospitalarios aragoneses por parte de la monarquía ${ }^{72}$. Como ya hemos señalado, una de las condiciones fijadas en 1317 para la absorción de este patrimonio fue que todos los oficiales sanjuanistas de la Corona de Aragón tuvieran que prestar juramento y homenaje al rey antes de tomar posesión de sus cargos ${ }^{73}$. La documentación conservada nos muestra que esta práctica se observó rigurosamente durante los siglos XIV y XV. Más arriba ya citamos cómo el castellán de Amposta prestó juramento de fidelidad y homenaje a Jaime II en $1317^{74}$.

Tanto el pontificado como la monarquía vigilaron el cumplimiento de la práctica durante los primeros años. El papa Juan XXII obligó a prestar el juramento y el homenaje al nuevo prior de Cataluña en $1319^{75}$. Ese mismo año el baile general de Aragón informaba al monarca que los comendadores aragoneses nombrados en un capítulo de la Orden todavía no habían hecho el jura-

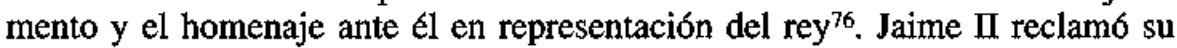

\footnotetext{
70 J. MIRET Y SANS, Les cases de Templers y Hospitalers en Catalunya, Barcelona 1910, pp. $390-395$

11 AHN, Ordenes Militares, carpeta 869, n. 19.

72 A. LuTTRELL, The Hospitallers of Rhodes and their Mediterranean World, Aldershot 1992, III, p. 84.

73 S. PAULI, Codice diplomatico del sacro militare ordine Gerosolimitano, Lucca 1733-1737, II, pp. 53-55.

${ }^{74}$ AHN, Ordenes Militares, carpeta 528, n. ${ }^{\circ} 692$.

75 J. VINCKE, Documenta selecta mutuas civitatis Arago-Catalaunicae et ecclesiae relationes illustrantia, Barcelona 1936, pp. 246-249.

${ }^{76}$ F. DE MOXó Y MONTOLIU, La casa de Luna (1276-1348). Factor poltico y lazos de sangre en la ascensión de un linaje aragonés, Münster 1990, pp. 422-423.
} y 395 .

69 J. MiRet y SANS, Les cases de Templers y Hospitalers en Catalunya, Barcelona 1910, pp. 384

Proyección internacional de la iglesia hispana

Hispania Sacra 51 (1999) 
prestación a frey Sancho de Oros, comendador de Caspe y lugarteniente del castellán, en $1321^{77}$.

Posteriormente parece que la práctica se cumplió con regularidad. Por lo menos así lo documentamos en el caso del castellán de Amposta para los años 1396,1429 y $1493^{78}$.

Antes de terminar con el análisis del caso aragonés quizás sea interesante anotar que a mediados del siglo XIV también los antiguos bienes del Temple en el reino de Valencia estuvieron a punto de ser incorporados al Hospital. Al parecer, el rey Pedro IV de Aragón no estaba muy satisfecho con la eficacia de la Orden de Montesa y solicitó al papa la unión de dicha Orden a la de San Juan. En 1346 el pontífice Clemente VI llegó a encargar a los obispos de Barcelona y de Tarazona que estudiaran esta propuesta del monarca y le enviaran la información que recogieran al respecto ${ }^{79}$. Clemente VI falleció antes de tomar una decisión. Entonces el rey Pedro IV volvió a repetir su petición a su sucesor, Inocencio VI: Como éste carecía de noticias fidedignas sobre el asunto, encomendó al obispo de Huesca que recabara información en 1353. El prelado habría de escuchar los razonamientos tanto de los miembros de la Orden de Montesa como del monarca aragonés. Después remitiría una carta al pontífice con todos los datos recogidos ${ }^{80}$.

La situación fue tan grave para la Orden de Montesa que en 1355 un capítulo de dicha Orden requirió a su maestre que hiciera todo lo posible para evitar la proyectada incorporación al Hospital. El maestre así lo juró. Sin embargo, al año siguiente se llegaron a redactar las bases para la unión. Con todo, al final la anexión no tuvo efecto ${ }^{81}$.

El episodio que acabamos de referir nos pone de manifiesto que la solución aragonesa al problema del destino de los bienes templarios estuvo a punto de ser también su incorporación total al Hospital. Además, nos demuestra que todavía a mediados del siglo XIV no se consideraba como definitiva la solucion pactada entre Jaime II y Juan XXII en 1317. En cualquier caso, dentro del

77 J. VINCKE, Documenta selecta mutuas civitatis Arago-Catalaunicae et ecclesiae relationes illustrantia, Barcelona 1936, p. 260.

78 AHN, Órdenes Militares, carpeta 590 n. 219 y carpeta 708 n, 3. A. DE LA TORRE (Ed.), Documentos sobre relaciones intemacionales de los Reyes Católicos, Barcelona 1949-1966, IV, pp. 302303.

79 F. J. MiQuel Rosell, Regesta de letras pontificias del Archivo de la Corona de Aragón. Sección Cancillería Real (Pergaminos), Madrid 1948, p. 314.

80 S. PAULI, Codice diplomatico del sacro militare ordine Gerosolimitano, Lucca 1733-1737, II pp. 403-404.

81 Áurea Javierre Mur, Pedro IV el Ceremonioso y la Orden de Montesa: Martínez Ferrando archivero. Miscelánea de estudios dedicados a su memoria, Barcelona 1968, pp. 208-211 y 214-216. 
contexto peninsular el caso aragonés aparece como una vía intermedia entre las soluciones opuestas dadas al problema en Navarra y en Portugal.

\section{EL TRIUNFO DEL REY EN PORTUGAL.}

Portugal va a ser el reino peninsular donde los planes de la monarquía con respecto a los bienes templarios se impongan de forma más rotunda. El rey portugués va a conseguir del papa que todo este patrimonio pase a una nueva y pequeña orden militar, la de Cristo, fácilmente controlable por la monarquía. Los hospitalarios no recibirán nada.

De acuerdo con lo establecido por Clemente V el rey de Portugal, don Dionís, envió dos embajadores a Aviñón para negociar el destino de los bienes templarios en su reino. Al parecer, uno de ellos fue un hospitalario portugués ${ }^{82}$. Las conversaciones se prolongaron durante varios años. El monarca portugués mandó enviados suyos varias veces al papa Clemente $\mathrm{V}$ y a su sucesor, Juan XXII. A través de ellos expuso diversas razones y causas por las cuales las posesiones del Temple no podían ser incorporadas al Hospital sin evidente perjuicio y peligroso dispendio suyo y de su reino ${ }^{83}$.

En 1318 el rey don Dionís nombró procuradores suyos al caballero Juan Lorenzo y a Pedro Pérez, canónigo de Coimbra, para tratar con el papa Juan XXII algunas cuestiones. Entre ellas figuraba el problema de los bienes en otro tiempo templarios de su reino ${ }^{84}$. Fueron estos embajadores quienes finalmente llegaron a un acuerdo con el pontífice sobre el tema.

Además de señalar las objeciones a la incorporación al Hospital ya citadas del monarca portugués, los procuradores expusieron al papa los numerosos daños que los musulmanes hacían en los territorios de Portugal proximos a ellos. Propusieron como remedio la instalación de una nueva orden militar en el castillo de Castromarino, en el Algarve. Tras largo examen de la cuestión con los dos embajadores, el papa Juan XXII decidió fundar la orden militar de Cristo el 14 de marzo de 1319. Simultáneamente, asignó los antiguos bienes templarios en Portugal a la nueva Orden ${ }^{85}$.

Dos días más tarde, el pontífice escribió al rey don Dionís para comunicarle que había llegado a un acuerdo con sus enviados sobre las posesiones del Temple y le pidió que lo ratificase ${ }^{86}$. En efecto, el monarca portugués aprobó

\footnotetext{
82 L. DAILLIEZ, L'Ordre de Saint-Jean de Jerusalem au Portugal XI-XV siècles, Niza 1977, p. 46.

83 Monumenta Henricina, Coimbra 1960-1974, I, pp. 101+102.

84 Monumenta Henricina, Coimbra 1960-1974, I, pp. 88-90.

85 Monumenta Henricina, Coimbra 1960-1974, I, pp. 97-100.

86 Monwmenta Henricina, Coimbra 1960-1974, I, pp. 122-123.
}

Proyección internacional de la iglesia hispana Hispania Sacra 51 (1999) 
la ordenación del papa sobre la fundación de la Orden de Cristo el 5 de abril de $1319^{87}$.

La transferencia del patrimonio afectado parece que se realizó con rapidez durante los meses siguientes. El 20 de noviembre de aquel mismo año el maestre de la Orden de Cristo, Gil Martínez, y el convento de la misma Orden se dieron por satisfechos de la entrega de los antiguos bienes templarios y se comprometieron a no hacer ninguna reclamación en el futuro al monarca sobre ellos. Además, en consideración a los gastos realizados por el rey don Dionís durante su secuestro y por otras mercedes que había hecho a su Orden, le concedieron todas las rentas que había recibido de aquellos bienes hasta la fecha ${ }^{88}$.

De esta forma el caso portugués constituye el ejemplo más claro de victoria de la posición contraria a una incorporación del patrimonio templario al Hospital que tan general era entre las monarquías ibéricas. La solución alternativa que propugna la realeza, ya que era imposible la simple incautacion de una propiedad eclesiástica, es la constitución de pequeñas órdenes militares «nacionales» muy ligadas a la monarquía desde sus orígenes. El ejemplo de Portugal es sin duda el más diáfano a este respecto. Es posible que en el triunfo de las pretensiones del monarca portugués influyera el hecho que el priorato del Hospital en Portugal tenía una posición bastante marginal y periférica en el conjunto de la Orden durante los siglos XIV y XV ${ }^{89}$. Por este motivo quizás el interés del papa y de los altos dignatarios sanjuanistas en ampliarlo fuera menor.

\section{LA FALTA DE UNA SOLUCIÓN GLOBAL EN CASTILLA.}

El caso de la Corona de Castilla es probablemente el más caótico de toda la Península Ibérica. Teóricamente hubo una resolución pontificia, pero en la práctica se va a seguir una vía opuesta a la diseñada por el papa ${ }^{90}$.

La raíz del problema estriba en que, a diferencia de lo ocurrido en Portugal y Aragón, después de 1312 los monarcas castellanos no enviaron a sus embajadores para tratar con el papa el destino de los bienes templarios de sus reinos. Una vez expirado ampliamente el plazo previsto para la negociación, el pontífice consideró que debía tomar una decisión al respecto por sí mismo para evitar la disgregación del patrimonio afectado. El 14 de marzo de 1319 Juan

\footnotetext{
87 Monumenta Henricina, Coimbra 1960-1974, I, pp. 124-126.

${ }^{88}$ Monumenta Henricina, Coimbra 1960-1974, I, pp. 129-131.

${ }^{89}$ A. LUTTREL, Latin Greece, the Hospitallers and the Crusades 1291-1440, Londres 1982, I, pp. 256-257, 260-261.

90 CARLOS BARQUERo GoNi, El conflicto por los bienes templarios en Castilla y la Orden de San Juan: En la España Medieval, 16 (1993) 37-54.
} 
XXII dispuso que las antiguas posesiones del Temple en la Corona de Castilla pasasen a la Orden de San Juan ${ }^{91}$. Simultáneamente, el papa encomendó al prior del Hospital en Castilla y León, frey Fernán Rodríguez de Valbuena, la administración de dicho patrimonio ${ }^{92}$. Finalmente, también ese mismo día el pontífice mandó al obispo de Ávila, al arcediano de Sarria y a su capellán Buzolo de Parma, canónigo de la iglesia de Tournai, que hicieran entrar a la Orden de San Juan en la posesión de los bienes templarios en Castilla y León ${ }^{93}$.

El monarca castellano Alfonso XI, entonces menor de edad, con la autorización de su tutora, la reina doña María de Molina, ordenó en teoría el cumplimiento de la disposición pontificia en noviembre de $1319^{94}$. Sin embargo, de hecho las medidas tomadas por Juan XXII tuvieron muy poca efectividad. Desde 1308 la monarquía castellana ya había donado muchas de las antiguas posesiones templarias a la nobleza, a las Órdenes Militares peninsulares y a grandes concejos de realengo como el de Sevilla ${ }^{95}$. Todos estos beneficiarios ofrecieron una fuerte resistencia cuando los hospitalarios y los ejecutores pontificios comenzaron a exigirles la entrega de los bienes del Temple en 1319 y 1320.

El caso de la Orden de Calatrava es paradigmático a este respecto. Esta Orden tenía los antiguos lugares templarios de Capilla, Almorchón y Garlitos como prenda de un importante préstamo que había hecho a la Orden de Alcántara. Cuando en 1319 el comendador sanjuanista de Olmos, frey Roy González, le solicitó el traspaso de las citadas plazas, el maestre calatravo se negó a hacerlo y apeló al papa ${ }^{96}$. Más tarde, en 1320 , cuando el deán de Toledo y arcediano de Huete, Alonso Fernández, subejecutor de la medida pontificia, volvió a requerirle lo mismo, el maestre de nuevo hizo caso omiso y presentó apelación al papa contra este mandato ${ }^{97}$.

También en 1320 un freire del Hospital, Lope Suárez, solicitó al maestre de Alcántara la cesión de los castillos templarios que tenía su Orden. Alegando que

\footnotetext{
91 P. RodRfguez Campomanes, Disertaciones historicas del Orden y Caballerfa de los Templarios, Madrid 1747, pp. 235-240.

92 C. DE Ay ALA MARTíneZ (Compilador), Libro de privilegios de la Orden de San Juan de Jerusalén en Castilla y León (siglos XII-XV), Madrid 1995, pp. 662-664.

93 G. MOLLAT, Jean XXII (1316-1334). Lettres communes, París 1904-1947, II, p. 342.

94 P. ROORIGUEZ CAMPOMANES, Disertaciones históricas del Orden y Caballería de los Templar ios, Madrid 1747, pp. 234-241.

95 Carlos Estepa, La disolución de la Orden del Temple en Castilla y León: Cuadernos de Historia, 6 (1975) 164-167, 176-182. G. MARTINEZ DfEZ, Los templarios en la Corona de Castilla, Burgos 1993, pp. 259-262.

96 AHN, Órdenes Militares, carpeta 463, n. 209.

97 AHN, Órdenes Militares, carpeta 463, n. 210.

Proyección internacional de la iglesia bispana

Hispania Sacra 51 (1999)
} 
los tenía en homenaje del rey y que no podía entregarlos hasta que el monarca fuera mayor de edad, el maestre Suero Pérez se negó y apeló al pontífice ${ }^{98}$.

La nobleza laica tampoco estuvo dispuesta a dar los antiguos bienes del Temple que tenía a los hospitalarios. Un buen ejemplo de ello lo constituye don Juan Alfonso de Haro, señor de los Cameros ${ }^{99}$. En 1320 fue excomulgado a petición del prior del Hospital por detentar ilegalmente la bailía templaria de Alcanadre ${ }^{100}$. Otro caso parecido es el de Fernando Velasco Pimentel, quien también fue excomulgado en 1320 por haber tomado dos castillos del Temple que habían sido adjudicados a la Orden de San Juan: Burguillos y Alconchel ${ }^{101}$.

El papa Juan XXII reaccionó con rapidez contra las resistencias que había suscitado su decisión, aunque al final sus esfuerzos resultaron ser en gran medida infructuosos ${ }^{102}$. El 1 de mayo de 1320 mandó al arzobispo de Santiago y a los obispos de Lugo y de Córdoba que indujeran a los ocupantes de posesiones del Temple en Castilla a restituirlas a la Orden del Hospital. Si no lo hicieran en el plazo de un mes después de haber sido requeridos a ello, serían excomulgados. Las personas que opusieran resistencia habrían de ser citadas ante el pontífice en el plazo de dos meses ${ }^{103}$.

Ese mismo día el pontífice también tomó medidas contra la oposición presentada por las Órdenes Militares peninsulares. Juan XXII mandó a la Orden de Santiago que entregara los bienes templarios retenidos por ella en Castilla y León a la Orden de San Juan y a su prior en el plazo de un mes ${ }^{104}$. Simultáneamente el papa transmitió el mismo mandato a las Órdenes de Alcántara y de Calatrava ${ }^{105}$.

La aplicación de todas estas medidas pontificias va a suscitar numerosos pleitos en los que el papa va a tener que intervenir repetidamente. Entre ellos destaca especialmente el que enfrentó al Hospital con el Concejo de Sevilla por el dominio de Fregenal de la Sierra. Este antiguo castillo templario había pasado al municipio hispalense tras la disolución de la Orden. Posteriormente,

\footnotetext{
98 A. DE TORRES Y TAPLA, Crónica de la Orden de Alcántara, Madrid 1763, 1, pp. 522-524.

99 SALVADOR DE MOXó, La sociedad política castellana en la época de Alfonso XI: Cuadernos de Historia, 6 (1975) 226-227.

${ }^{100}$ AHN, Órdenes Militares, carpeta 573, n. ${ }^{\circ} 1$.

101 J. Solano DE Figueroa y AlTAMIRANO, historia eclesiástica de la ciudad y obispado de Badajoz, Badajoz 1931, 1." parte, III, pp. 262-263.

102 J. Delaville Le RoulX, Les Hospitaliers à Rhodes jusqu'à la mort de Philibert de Naillac (1310-142I), París 1913, pp. 45-46.

103 AHN, Ordenes Militares, carpeta 332, n. ${ }^{\circ} 10$.

104 A. F. AguAdO de CORDOBA, A. A. Alemán y ROSALES y J. LÓPEZ AGURLETA, Bullarium Equestris Ordinis S. Iacobi de Spatha, Madrid 1719, pp. $279-282$.

105 G. MOLLAT, Jean XXII (1316-1334). Lettres communes, París 1904-1947, III, p. 94.
} 
los hospitalarios hicieron promulgar una sentencia de entredicho sobre la ciudad para conseguir la reversión de la fortaleza. En 1322 Juan XXII encomendó el juicio de la causa al obispo de Sabina, Guillermo, legado apostólico. El entredicho eclesiástico sobre Sevilla se prolongó por este motivo durante seis años, hasta que en 1325 el papa ordenó relajarlo durante un breve periodo de tiempo al arzobispo hispalense ${ }^{106}$. Posteriormente el entredicho se reanudó hasta que lo puso fin un acuerdo entre el Concejo de Sevilla y la Orden de San Juan. El Concejo pagó 7.500 florines al Hospital por la posesión del castillo de Fregenal. Por su parte, la Orden retuvo las iglesias y los diezmos de la localidad $^{107}$. Esta concordia fue confirmada por el papa Benedicto XII en $1335^{108}$. Con el tiempo parece que el Hospital sólo conservó la percepción de la mayor parte del diezmo eclesiástico. A partir de esta base se formó la nueva encomienda sanjuanista de Fregenal de la Sierra ${ }^{109}$.

Otros pleitos enfrentaron a los hospitalarios con las Órdenes Militares peninsulares. El maestre de Calátrava, García López, fue excomulgado a instancias del prior del Hospital en Castilla a pesar de que devolvió los castillos templarios que tenía al maestre de Alcántara. En 1324 el pontífice Juan XXII mandó primeto al arzobispo de Santiago y después al obispo de Astorga que decidiesen sobre aquella excomunión lo que fuera justo ${ }^{110}$.

Por su parte el maestre de Alcántara, Suero Pérez, también fue excomulgado y la tierra de su Orden puesta bajo el entredicho eclesiástico por iniciativa del prior del Hospital ya que le no restituyó las antiguas fortalezas templarias de Capilla, Almorchón y Garlitos. En 1323 Juan XXII confió el juicio de esta causa al obispo de Avila'11. Sin embargo, el contencioso se prolongó durante más de una década. En 1335 el papa Benedicto XII concedió facultad al obispo de Palencia para que hiciera suspender la excomunión del maestre y el entredicho sobre los castillos afectados durante año y medio. El motivo era que había negociaciones esperanzadoras en curso entre el rey Alfonso XI de Castilla y la Orden del Hospital para conseguir la devolución de aquellos castillos o alguna satisfacción en su lugar ${ }^{12}$. Desconocemos el resultado final de las conversa-

\footnotetext{
106 G. MOLLAT, Jean XXII (1376-1334). Lettres communes, París 1904-1947, IV, p. 78 y VI, p. 37.

107 J. DeLAVILle Le RoulX, Les Hospitaliers à Rhodes jusqu'a la mort de Philibert de Naillac (1310-1421), París 1913, pp. 67-68.

108 J. M. VIDAL, Benoit XII (1334-1342). Lettres communes, París 1906-1911, I, p. 199.

109 MARÍA DE LAS MERCEDES BoRRERO FERNÁNDEZ, Fregenal de la Sierra. Una villa sevillana en la jurisdicción eclesiástica de Badajoz: Revista de Estudios Extremefios, 34 (1978) 502-504.

110 G. MOLLAT, Jean XXII (1316-1334). Lettres communes, París 1904-1947, V, pp. 70 y 83.

III G. MOLLAT, Jean XXII (1316-1334). Lettres communes, París 1904-1947, IV, p. 339.

112 J. M. VIDAL, Benoit XII (1334-1342). Lettres closes et patentes intéressant les pays autres que la France publiées ou analysées d'après les registres du Vatican, París 1913-1950, I, pp. 49-51.
} 
ciones. En cuanto a la excomunión del maestre de Alcántara, parece que un jurisconsulto llamado Oldrado logró su absolución del pontífice ${ }^{13}$.

Al final sólo una pequeña proporción đe las posesiones templarias en Castilla pasó efectivamente al Hospital ${ }^{114}$. Sin embargo, en muchos casos parece tratarse de incorporaciones sólo transitorias. Sabemos que el caballero Raimundo de Cardona entregó las fortalezas templarias de Alconchel, Burguillos y Jérez de los Caballeros a la Orden de San Juan porque en 1320 el papa Juan XXII mandó al prior del Hospital en Castilla que hiciera restituir a este noble los bienes muebles que había dejado en aquellos castillos ${ }^{115}$. El dominio sanjuanista sobre estas plazas debió ser efímero, pues conocemos que posteriormente, en el mismo siglo XIV, estaban en otras manos ${ }^{16}$.

Otro antiguo castillo templario, el de San Pedro de Latarce, pasó efectivamente al Hospital sólo durante un corto periodo de tiempo. En 1327 el papa Juan XXII autorizó al prior de la Orden de San Juan en Castilla para que permutara con Alvaro Núñez de Osorio dicha fortaleza y la casa de Villalobos por los derechos reales de las bailías hospitalarias del Valle de la Guareña, Castronuño, Villaescusa, Fresno el Viejo, Paradinas de San Juan, Cuenca y Wamba ${ }^{117}$.

La bailía templaria de Villapalmaz también se integró en la Orden de San Juan, aunque en seguida los hospitalarios se desprendieron temporalmente de ella. En 1330 la cedieron vitaliciamente a Pedro Álvarez Osorio a cambio de la donación perpetua a la Orden de 10 yugadas de heredad escalonadas desde la villa de Benavente hasta el puerto de Heirado ${ }^{118}$. Otra antigua bailía templaria que, al parecer, pasó al Hospital fue la de Alcanadre. En 1337 un freire sanjuanista, Rodrigo Alfonso, aparece citado como comendador de Alcanadre ${ }^{119}$. Sin embargo, el dominio hospitalario debió de ser fugaz pues en 1342 el rey Alfonso XI donó todo lo que el Temple había tenido en Alcanadre y en su término al monasterio de las Huelgas Reales de Valladolid ${ }^{20}$.

Un nuevo ejemplo de disfrute momentáneo de la Orden de San Juan sobre una antigua propiedad templaria lo encontramos en Andalucía. Sabemos que

\footnotetext{
113 A. DE TORRES Y TAPIA, Crónica de la Orden de Alcántara, Madrid 1763, I, p. 524.

114 CaRlos ESTEPA, La disolución de la Orden del Temple en Castilla y León: Cuademos de Historia, 6 (1975) 171-172, 174-176, 182-185.

115 G. MOLLAT, Jean XXII (1316-1334). Lettres communes, París 1904-1947, III, p. 107.

116 Carlos EstePa, La disolución de la Orden del Temple en Castilla y León: Cuadernos de Historia, 6 (1975) 177, 178, 181.

17 CARLOS DE AYALA MARTfNeZ o OTROS, Algunos documentos sobre Ordenes Militares y forralezas: Castellum, 1 (1992), 99-100.

118 AHN, Órdenes Militares, legajo 7864, Donaziones hechas a la Religion de San Juan de encomiendas y agregaziones por diferentes reyes Catholicos, con sus confirmaziones.

119 AHN, Órdenes Militares, carpeta 939, n. 39.

120 G. MART́́nEZ DÍEZ, Los templarios en la Corona de Castilla, Burgos 1993, pp. 268-269.
} 
las quince yugadas que el Temple poseía cerca de Almodóvar del Río pasaron posteriormente a los hospitalarios, pero hacia 1341 las tenía Domingo Fernández por Gonzalo Martínez, despensero del rey ${ }^{121}$.

El último caso que hemos encontrado documentado de un patrimonio templario transferido a la Orden de San Juan es el de las posesiones del Temple en Medina del Campo. Una vez más, el periodo de disfrute hospitalario parece que fue bastante corto. Conocemos que fray García González Bogía, lugarteniente del maestre y convento de Rodas en el priorato de Castilla y León, permutó con Diego Fernández de Medina las tierras y heredades que la Orden del Temple y el Hospital tenían en Medina del Campo por lo que Diego poseía en Villoria, aldea de Salamanca. En 1357 el entonces prior de la Orden de San Juan en Castilla y León, Juan Fernández de Heredia, confirmó este intercambio, cuya fecha desafortunadamente no conocemos ${ }^{122}$.

Según acabamos de comprobar, los hospitalarios no retuvieron en sus manos buena parte de las escasas posesiones templarias que recibieron en Castilla. Probablemente en muchos casos su dispersión geográfica les forzó a realizar permutas para poder reunir las nuevas propiedades con el patrimonio sanjuanista primitivo. Además, seguramente vendieron parte para hacer frente a las graves dificultades financieras que la Orden de San Juan en su conjunto sufrió a comienzos del siglo XIV ${ }^{123}$. En el caso de Castilla sabemos que con este motivo el papa Juan XXII les autorizó a enajenar una casa de cada dos en $1322^{124}$. Finalmente, también pudo influir la hostilidad de la monarquía castellana a la incorporación de los bienes templarios al Hospital que comprobaremos más adelante.

En cualquier caso, to que es seguro es al menos un cierto número de posesiones del Temple pasó a la Orden de San Juan en Castilla ya que sabemos que los hospitalarios tuvieron que asumir la carga de mantener a los antiguos templarios castellanos que estaba aneja a dichos bienes. En efecto, los miembros de la Orden del Temple en Castilla fueron declarados inocentes en el Concilio provincial de Salamanca de $1310^{125}$. En consecuencia, de acuerdo con las disposiciones del Concilio de Vienne de 1312, estos templarios debían recibir

121 ManUel Nieto CumPlido, El libro de diezmos de donadios de la Catedral de Córdoba: Cuadernos de Estudios Medievales, IV-V (1979) 137-138 y 158.

122 AHN, Códices, 602-B, f. 157v.

123 A. LUTTREL, The Hospitallers in Cyprus, Rhodes, Greece and the West. 1291-1440, Londres 1978, VIII, p. 318.

124 J. Delaville Le Roulx, Les Hospitaliers à Rhodes jusqu'à la mort de Philiberi de Naillac (1310-1421), París 1913, p. 54.

125 G. MARTínez Diez, Los templarios en la Corona de Castilla, Burgos 1993, pp. 241-244. GONZALO MARTÍNEZ DIEZ, El proceso de disolución de los templarios. Su repercusión en Castilla: Los monjes soldados. Los templarios y otras Órdenes Militares, Aguilar de Campoo 1996, pp. 101-102.

Proyección internacional de la iglesia hispana Hispania Sacra 51 (1999) 
pensiones vitalicias con cargo a sus antiguos bienes. Los arzobispos y otros prelados de los reinos de Castilla y León asignaron unos estipendios a los antiguos miembros de la Orden suprimida en consonancia con los decretos de dicho Concilio. Sin embargo, cuando los hospitalarios recibieron el patrimonio del Temple en Castilla se encontraron con que estas pensiones absorbían casi todas las rentas templarias. Debieron tener dificultades para seguir abonándolas, por lo que los arzobispos castellanos emitieron sentencias de excomunión y entredicho contra el maestre y los freires del Hospital en concilios provinciales. Finalmente el papa Juan XXII tuvo que intervenir. En 1324 ordenó al chantre de la Catedral, al prior de los dominicos y al guardián del convento de los franciscanos de Salamanca que moderasen aquellas pensiones y que revocasen las citadas sentencias ${ }^{126}$. A pesar de todo, posteriormente siguió habiendo problemas con los pagos. En 1326 el mismo pontífice hubo de mandar al arzobispo de Santiago que hiciera que el prior del Hospital abonase a dos antiguos templarios el dinero que les debía sobre las rentas de las casas de Pajares de Lampreana, San Miguel de Ayres, Zamora y Mayorga ${ }^{127}$.

Con todo, es indudable que la mayoría de las posesiones templarias en Castilla nunca llegó a incorporarse a la Orden de San Juan por la oposición de la monarquía. Entre 1320 y 1331 el papa Juan XXII escribió varias veces al rey Alfonso XI, al conde de Trastámara, al prior castellano del Hospital y a la reina María de Molina para conseguir la transferencia pero sus gestiones no tuvieron éxito por la oposición del monarca ${ }^{128}$. En efecto Alfonso XI, ya mayor de edad, pretendía conseguir una solución al problema similar a la de Portugal: la creación de una nueva Orden Militar con los bienes del Temple en su reino. Sin embargo, su propuesta fue rechazada por Juan XXII en 1331. El motivo alegado por el pontífice era que la experiencia había enseñado que las nuevas Órdenes de Montesa y de Cristo estaban tan ocupadas en sus asuntos internos que no proporcionaban ningún servicio al exterior. En cambio, el papa aseguraba al rey castellano que los hospitalarios le prestarían una asistencia mucho mayor y más rápida que cualquier otra nueva Órden Militar ${ }^{129}$.

${ }^{126}$ G. MOLLAT, Jean XXII (1316-1334). Lettres communes, París 1904-1947, V, p. 169.

127 J. DELAVILLE LE RouLX, Les Hospitaliers a Rhodes jusqu'à la mon de Philibert de Naillac (I3I0-1421), París 1913, p. 48.

128 J. Delaville Le RoulX, Les Hospitaliers à Rhodes jusqu'a la mort de Philiber de Naillac (1310-1421), París 1913, pp. 45-46.

${ }^{129}$ S. PAULI, Codice diplomatico del sacro militare ordine Gerosolimitano, Lucca 1733-1737, II, p. 80.

Proyección internacional de la iglesia hispana Hispania Sacra $51(1999)$ 
Al final no hubo acuerdo y Alfonso XI siguió disponiendo a su antojo de la mayor parte del patrimonio del Temple en Castilla ${ }^{130}$. Sin embargo, el pontificado continuó reclamando a la monarquía castellana una solución global del problema. Sabemos que entre 1353 y 1356 el papa Inocencio VI volvió a realizar gestiones ante el rey Pedro I de Castilla para conseguir la transferencia de los bienes templarios al Hospital, pero parece que tampoco tuvo éxito ${ }^{131}$.

En 1366 otro pontífice, Urbano V, encargó a los obispos de Lérida y de Segovia y al abad del monasterio de Psalmedi que volvieran a reclamar aquel patrimonio al monarca castellano para la Orden de San Juan ${ }^{132}$. Esta vez las circunstancias eran más favorables. Pedro I acababa de ser destronado por Enrique II de Trastámara y la posición del nuevo monarca durante su primer reinado era muy insegura, por lo que necesitaba granjearse todos los apoyos posibles ${ }^{13}$. En 1367 el rey Enrique II de Castilla llegó a prometer al castellán de Amposta, Juan Fernández de Heredia, que obedecería los mandatos pontificios sobre el tema. Un capítulo general del Hospital celebrado en Rodas en 1370 autorizó al maestre de la Orden para ratificar las conversaciones entabladas por Heredia para obtener la restitución de los bienes del Temple en Castilla. Sin embargo, una vez más parece que no hubo ningún resultado concreto ya que en 1377 el papa Gregorio XI volvía a reclamar la devolución de aquel patrimonio ${ }^{134}$.

Durante la segunda mitad del siglo XIV apareció una interesante propuesta para zanjar la cuestión. Se trataba de permutar las posesiones del Temple en Castilla por las que las Órdenes de Calatrava y Santiago tenían en Aragón ${ }^{135}$. La idea estaba bastante bien pensada. En efecto, las Órdenes Militares peninsulares habían recibido buena parte del patrimonio templario por concesión de la monarquía castellana ${ }^{136}$. Además, tanto Calatrava como Santiago disponían

130 G. MARTínEZ DíEZ, Los templarios en la Corona de Castilla, Burgos 1993, pp. 268-269. Gonzalo Martínez DíEz, El proceso de disolución de los templarios. Su repercusión en Castilla: Los monjes soldados. Los templarios y otras Órdenes Militares, Aguilar de Campoo 1996, p. 104.

13! J. ZUNZUNEGUI ARAMBURU, Bulas y cartas secretas de Inocencio VI (1352-1362), Roma 1970, pp. 43-44, 58-61, 63-64, 203-204, 219.

132 J. DelaVILLE Le RoulX, Les Hospitaliers à Rhodes jusqu'à la mort de Philibert de Naillac (1310-1421), París 1913, pp. 46-47.

133 J. VALDEÓN BARUQUE, Enrique II de Castilla. La guerra civil y la consolidación del régimen (1366-1371), Valladolid 1966, pp. 100-149.

134 J. DELAvilLe Le RoULX, Les Hospitaliers à Rhodes jusqu'à la mort de Philibert de Naillac (1310-1421), París 1913, pp. 47 y 167.

135 A. LUTTRELL, The Hospitallers in Cyprus, Rhodes, Greece and the West. 1291-1440, Londres 1978, XII, pp. 73-74.

136 Carlos Estepa, La disolución de la Orden del Temple en Castilla y León: Cuadernos de Historia, 6 (1975) 180-182.

Proyección internacional de la iglesia hispana

Hispania Sacra 51 (1999) 
de unos respetables señoríos en Aragón ${ }^{137}$. En 1356 el maestre del Hospital otorgó a su lugarteniente, frey Juan Fernández de Heredia, castellán de Amposta y prior de Castilla, la potestad de conceder el hábito de la Orden de San Juan. El motivo de la concesión era poder convertir a los miembros aragoneses de Ias Órdenes de Santiago y Calatrava en hospitalarios en el caso de que $\mathrm{He}-$ redia consiguiera recuperar los bienes templarios en Castilla y permutarlos por los de Santiago y Calatrava en Aragón ${ }^{138}$.

El pontificado acogí con mucho interés el proyecto. En 1372 el papa Gregorio XI ordenó al legado apostólico, Guido, que se informara del valor que tenían los bienes templatios ocupados por el rey y por los nobles en Castilla y del de las de las posesiones de las órdenes de Calatrava y Santiago en Aragón. Después habría de requerir la aprobación de estas dos órdenes para realizar la permuta o las razones que alegasen para oponerse. Finalmente, el legado tendría que enterarse de si el monarca castellano estaría más dispuesto a devolver los bienes templarios a Calatrava y Santiago que al Hospital. Guido habría de dar cuenta al papa del resultado de todas estas gestiones ${ }^{139}$. En 1375 el mismo Gregorio XI llegó a pedir al rey Enrique II de Castilla que restituyera el patrimonio del Temple a los hospitalarios para efectuar aquel intercambio ${ }^{140}$. Sin embargo, el proyecto no llegó a materializarse ya que en el siglo XV las órdenes de Calatrava y de Santiago conservaban sus posesiones aragonesas ${ }^{141}$.

En definitiva, a pesar de todos los esfuerzos parece que nunca se concretó ningún acuerdo entre las partes interesadas. De esta manera la Orden de San Juan no pudo obtener la mayor parte de los bienes templarios en Castilla a pesar de la decisión pontificia a su favor. Finalmente la solución de facto dada al problema por la monarquía se impuso a la legal emitida por el papa.

137 R. SÁINZ DE LA MAZA LASOli, La Orden de Santiago en la Corona de Aragón. La encomienda de Montalbán (1210-1327), Zaragoza 1980, 488 pp. R. SÁlNZ DE LA MAZA LASOLI, La Orden de Santiago en la Corona de Aragón (II). La encomienda de Montalban bajo Vidal de Vilanova (1327. 1357), Zaragoza 1988, $271 \mathrm{pp}$. C. LALIENA CORBERA, Sistema social, estructura agraria y organización del poder en el Bajo Aragón en la Edad Media (siglos XII-XV), Teruel 1987, 313 pp.

${ }^{138}$ AHN, Códices, 602-B, f. 2v.

$139 \mathrm{~J}$. VINCKE, Documenta selecta mutuas civitatis Arago-Catalaunicae et ecclesia relationes illustrantia, Barcelona 1936, pp. 493-494.

$140 \mathrm{G}$. Bosio, Dell'Istoria della sacra religione et illustrissima militia di San Giovanni Gierosolimitano, Roma 1621, II, p. 120.

141 ALFONSO FRANCO SILVA, Rentas y vasallos de las Ordenes Militares de Santiago y Calatrava en la Corona de Aragón durante el siglo XV: Anuario de Estudios Medievales, 18 (1988) 511-523. 


\section{CONCLUSIONES.}

El caso del destino sufrido por las posesiones del Temple nos ofrece un interesante ejemplo de transferencia de patrimonio eclesiástico a gran escala en el siglo XIV. La gran beneficiaria a nivel europeo, la Orden del Hospital, también lo fue en la Península Ibérica aunque con especiales dificultades.

Las monarquías peninsulares opusieron fuerte resistencia a la ampliación de las posesiones hospitalarias en tal grado probablemente por tratarse de una Orden internacional y, por consiguiente, de difícil control por los reyes ibéri$\cos$. Como alternativa proponían la creación de unas pequeñas órdenes militares en cada reino, seguramente porque así serían mucho más fácilmente influenciables por sus respectivos soberanos. El pontificado, en cambio, apoyaba la incorporación de los bienes templarios en la Orden de San Juan probablemente porque tenía interés en que siguieran cumpliendo su primitiva función de apoyo a la cruzada.

Al final las soluciones concretas variaron en cada reino y fueron el producto de una compleja y particularizada negociación de cada monarca con el papa. El resultado final implicó una gran expansión patrimonial para los hospitalarios hispanos. La distribución geográfica de dicho crecimiento fue, sin embargo, muy irregular. Se concentró preferentemente en el Norte de la Península Ibérica y, más concretamente, en Navarra, Aragón, Cataluña y Mallorca. En cambio, el aumento patrimonial fue mínimo en la Corona de Castilla. En Portugal el número de las posesiones sanjuanistas permaneció inalterado mientras que disminuyeron mucho en el reino de Valencia.

En cualquier caso, vista en su conjunto, la recepción de los bienes templarios significó para la Orden del Hospital seguramente su mayor fuente de crecimiento patrimonial en la Península Ibérica durante la Baja Edad Media. 